\title{
Moisture prediction of sweet potato-quinoa-kiwicha flakes dried by rotary drum dryer using artificial intelligence
}

\author{
Vásquez-Villalobos, Víctor ${ }^{1, *}$; Hernández-Bracamonte, Orlando. ${ }^{2}$; Rojas-Naccha, \\ Julio'; Ninaquispe-Zare, Viviano'; Rojas-Padilla, Carmen $^{1}$; Vásquez-Angulo, Julia ${ }^{3}$ \\ 1 Departamento de Ciencias Agroindustriales. Universidad Nacional de Trujillo, Av. Juan Pablo I/ s/n. Trujillo, Peru. \\ 2 Departamento de Matemáticas. Universidad Nacional de Trujillo, Av. Juan Pablo II s/n. Trujillo, Peru. \\ ${ }^{3}$ Escuela de Ingeniería Agroindustrial. Universidad Nacional de Trujillo, Av. Juan Pablo I/ s/n. Trujillo, Peru.
}

Received December 1, 2015. Accepted January 4, 2018.

\begin{abstract}
A bi-factorial experimental design was considered to assess moisture variation of sweet potato-quinoa-kiwicha flakes (SP-Q-K) caused by the changes in the rotational speed and steam pressure of a rotary drum dryer (RDD). As it is a design with discrete variables, there is a limitation in the modeling and optimization thus techniques of Artificial Intelligence (Al): Artificial Neural Networks (ANN), Fuzzy Logic (FL) and Genetic Algorithms (GA), were applied, and their prediction ability evaluated. Due to the limitation of data for proper training, the ANN did not allow a correct prediction of the experimental data. Response Surface Methodology (RSM) was employed to obtain the relational equation among the experimental variables, which was used as the objective function with GA, and this allowed moisture optimization. Because of this, it is recommended to integrate RSM and GA into optimization studies. In this research the use of FL among variables, enabled us to get the best prediction adjustment of experimental values $\left(R^{2}=0.99\right)$, with a mean absolute error of $0.6 \pm 0.66 \%$, setting a pressure value of $5 \mathrm{~atm}$ and a speed value of $6 \mathrm{rpm}$ for flakes at $4.99 \%$ humidity.

Keywords: Artificial Neural Networks; Fuzzy Logic; Response Surface; Genetic Algorithms; Rotary Drum Drying.
\end{abstract}

\section{Introduction}

The consumption of breakfast cereals is associated with the supply of energy and nutrients, influenced by their level of promotion and labeling (Devi et al., 2014). Sweet potato (SP) (Ipomoea batatas), combined with quinoa (Q) (Chenopodium quinoa) and kiwicha (K) or amaranth (Amaranthus caudatus) can be used for the production of dehydrated breakfast flakes. Ramos et al. (2013) have reported the use of amaranth, $Q$ and kañiwua (Chenopodium pallidicaule) in corn-based extruded snacks, obtained through a double screw extruder. $\mathrm{SP}$ is rich in starch, dietary fiber, sporamin, phosphorus, $\beta$-carotene, phenolic acids and anthocyanins (Wang et al., 2016). Due to its characteristics, as it can be processed easily in the form of cooked puree, RDD can

\footnotetext{
* Corresponding author

E-mail: vvasquez@unitru.edu.pe (V. Vásquez-Villalobos).
}

be used as an alternative for its dehydration (Woolfe, 1992). SP flakes are considered as an alternative food when taken as breakfast cereals (Sjafrina and Aminah, 2014). Q is a pseudo-cereal with high value nutrition, rich in protein, fat, fiber, vitamins and minerals with an extraordinary balance of essential amino acids (Navruz-Varli and Sanlier, 2016). $K$ is a pseudocereal with a good source of starch, protein with a suitable balance of amino acids, high content of pectic substances and xyloglucans, lipids with high amount of squalene, vitamins $B$ complex and minerals (Paucar-Menacho et al., 2017).

According to Milczarek et al. (2017), the RDD is a device that enables the dehydration of purees, syrups, potato and SP pulp. Process conditions can be optimized according to the residence time of 
the product on the surface and the steam pressure/temperature inside that determines the temperature at the surface of the drum, and is transferred to the product. RDD allows you to use high temperatures (100$120^{\circ} \mathrm{C}$ ) in a short drying time, making it possible to improve the retention of bioactive compounds (Galaz et al., 2017).

RSM consists of a set of mathematical and statistical techniques for the development of relationships between the response of interest and a number of associated variables. It is useful for applications in which there are no reliable mathematical models to establish such a relationship, which can be approximated with a low grade polynomial model. It is also useful in cases where experimental data is expensive (Martinez-Conesa et al. 2017). Empirical models have been developed using conventional approaches such as factorial design, statistical regression, RSM, etc. On the other hand, among other models, there also those based on Artificial Intelligence (AI) as Artificial Neural Networks (ANN), Fuzzy Logic (FL) and Genetic Algorithms (GA) (Kant and Singh, 2015). Al is the art of creating machines to perform functions that require human intelligence. It is based on four system categories that: a) think like humans, b) act as humans, c) think rationally and d) act rationally. After two decades it has been observed that $\mathrm{Al}$ and the knowledge based systems, have been developed and used in different fields of science and technology (Nasiri et al., 2017). ANN have been used to predict dehydration processes (Guiné et al., 2015; Nadian et al., 2015; Muddle et al., 2017, Azadbakht et al., 2017). ANN are computational models that reproduce the shape of the human brain processes information, relating the input variables with a desired output, through a complex network. ANN are trained to produce a desired output from the input variables, using an iterative process of calculating and minimizing error, which is reduced to the minimum through the manipulation of weights associated with links between the layers of the ANN through a process known as Backpropagation (Muddle et al., 2017).

FL emulates human reasoning using imprecise information to generate decisions. Unlike traditional approaches, which require a mathematical understanding of the system, FL proposes an alternative way of processing, which allows to model complex systems through the use of human knowledge, through rules that depend only on the expert's experience. In these circumstances, each fuzzy rule represents an expert observation that models the conditions under which candidate's solutions; they have been modified in order to achieve the optimum location (Díaz-Cortés et al., 2017).

GA are the most popular optimization algorithms, often used for solving complex optimization problems. GA has a number of advantages which include the ability to work both with continuous as well as discreet variables and have a great potential for the application of parallel computing techniques, which allows you to reduce the processing time. Since its introduction in 1975 , important developments in various components have been made, such as chromosomes encoding, crossover, mutation and selection, providing a probability guarantee for a global optimum solution, which decreases when the size of the problem increases. It is thus desirable to find the best global solution, with a highest probability of success (Dao et al., 2017).

Considering that the humidity of the CQKbased breakfast flakes is an important factor in their conservation, a bifactorial experimental design was proposed in the present investigation to evaluate the variation of moisture due to the changes of the rotational speed and steam pressure of the RDD. The bifactorial design relates variables in a discrete way, so it is limiting for modeling and optimization. In this sense, knowing the potential of Al techniques, they were applied to the experimental data obtained, in order to evaluate their usefulness in these cases and their prediction capacity.

\section{Material and methods \\ Materials and equipment}

Yellow SP, white $Q$ flour (a variety from Junín) and Oscar Blanco $K$ flour variety were used, mixed in puree form, and then dosed by an auxiliary roller without heating (ARWH) into a RDD of $0.6 \mathrm{~m}^{2}$ steam heated surface (Figure 1).

A stainless steel blade scraper (SBS) was used to separate dehydrated flakes. The steam was supplied by a boiler at $8.2 \mathrm{~atm}$, whose pressure was regulated with the valve at 3 and $5 \mathrm{~atm}$. A motor with gears and a pulley system allowed us to modify the rotational speed of the RDD. The steam supply to the RDD was done through a mechanical seal, allowing its dosage, simultaneously with the drum rotation. When steam transfers heat to the puree impregnated on the RDD outer surface, its temperature increases almost instantneously, and the steam is condensed inside, it gets out through the mechanical seal and 
this allows a continuous operation. To determine the moisture, analytical balance of $600 \pm 0.01 \mathrm{~g}$ was used, and a drying stove with maximum temperature of $300 \pm 5^{\circ} \mathrm{C}$.

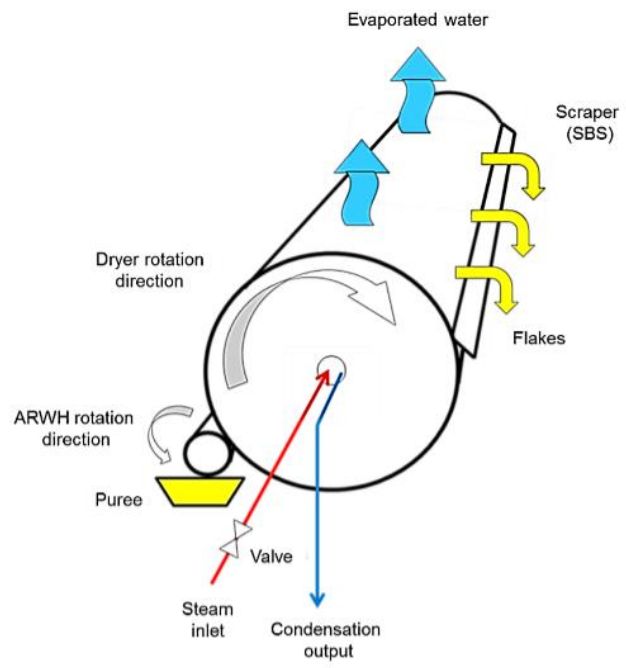

Figure 1. RDD elements and its operation scheme.

\section{Methodology}

A bifactorial design was used to assess the SPQK-based flakes moisture obtained by the effect of the variation on the rotational speed $(4,7$, and $11 \mathrm{rpm})$ and steam pressure (3 to $5 \mathrm{~atm}$ ) of the RDD (18 treatments). The $Q$ flour was mixed with $K$ flour and cooked SP in proportions of 15, 15 and $70 \%$ respectively; then water was added to obtain a puree to feed into a dryer with $80 \%$ moisture. Flakes samples were taken randomly in order to determine their moisture. As the researchers are aware of the Al techniques potential (ANN, FL and GA), these were applied to the experimental data obtained in order to assess their usefulness in these cases and their prediction capacity. ANN were employed to obtain an equation for experimental variables, which was used as an objective function with GA. Matlab software was used for ANN and GA (Trial Package, license: 3408337, GNU Octave 4.2.0 software (https://ftp.gnu.org/gnu/octave/windows/)

for $F L$ and Statistica software (wWw.statsoft/support/free-statistica-9trial/) for RSM.

\section{Artificial neural networks (ANN)}

$66.7 \%$ of the data for the ANN training (corresponding to treatments $3,4,5,8,9$, $10,11,12,13,15,16,17)$ were selected randomly from 18 treatments (independent variables: pressure and speed, and response variable: moisture) and $33.3 \%(1$, $2,6,7,14,18)$ to validate the ANN. ANN architecture was then set up in the Window- software sheet, using learning algorithm with Backpropagation training, and Levenberg-Marquardt weights adjustment to accelerate error search (Nawi et al. 2013, Cheng et al., 2016).

\section{Fuzzy logic (FL)}

GNU Octave software with fuzzy-logictoolkit was used to determine the final moisture (response) of SPQK flakes, through the operation of fuzzy sets intersections (and) for speed (rpm) and pressure (atm) entries. Gaussian membership interrelation was used based on the Mamdani method for defuzzification, as recommended by Amelia (2012). The moisture average values were obtained as a result of RDD speed and pressure (Table 1).

\section{Response surface methodology (RSM)}

18 treatments and their interrelations of independent variables of speed ( $\mathrm{rpm})$ and pressure (atm) with the dependent variable (dehydrated flakes moisture) were introduced to the software spreadsheet. Working with pure error, regression coefficients and ANOVA table with $95 \%$ significance were obtained, these data allowed us to carry out the variance analysis of the model regression coefficients. A two-dimensional projection graph was drawn up (Figure 8).

\section{Genetic algorithms (GA)}

Carvalho et al. (2012) reported moisture in breakfast cereals between 3.74 and $5.11 \%$. Within these values $5 \%$ moisture has been considered as suitable, and according to the contours surface determined by RSM, a low value and a high value of the independent variables pressure $x(1)$ and speed $x(2)$ located within the area desired (around $5 \%$ ) were delimited. The mathematical function obtained by RSM was used as a target function, and Lower and Upper limitations were established through Solver ga-Genetic Algorithm, having set up beforehand the number of stop iterations and the desired graphic display.

\section{Results and discussion}

Table 1 shows the moisture values obtained from the drying process. In this Table it can be observed that the lower moisture obtained was between $2.88 \%$ to $3.45 \%$ at $5.0 \mathrm{~atm}$ pressure and $4 \mathrm{rpm}$ speed and the higher moisture obtained was $9.44 \%$ at 5 atm and $11 \mathrm{rpm}$.

Analysis of variance of the bifactorial model for the flakes moisture percentages, showed a highly significant difference ( $p<$ 0.05 ) between pressure treatments (Fcal = $8.36>$ Ftab $=4.75$ ) and speed treatments $($ F cal $=10.39>$ Ftab $=3.89)$, as well as their 
iteration (Fcal $=10.55>$ Ftab $=3.89)$. A Duncan's test with a significance level of $95 \%$, allowed us to set values of $3 \mathrm{~atm}$ and 7 rpm for obtaining flakes at $5.83 \%$ humidity; it is not possible to perform modeling through this method, because of the limitation to determine the curvature in a place that is not the central point. Galaz et al. (2017) used a double-drum dryer at pilot scale for dehydrating thawed pomegranate peel.

\section{Table 1}

Moisture in SPQK-based dehydrated flakes obtained by operational pressure and rotational speed variations of the RDD

\begin{tabular}{cccc}
$\begin{array}{c}\text { Treatmen } \\
\text { ts }\end{array}$ & $\begin{array}{c}\text { Pressure } \\
(\text { atm })\end{array}$ & $\begin{array}{c}\text { Speed } \\
(\mathrm{rpm})\end{array}$ & $\begin{array}{c}\text { Moisture } \\
(\%)\end{array}$ \\
\hline 1 & 3 & 4 & 7.17 \\
2 & 3 & 4 & 7.97 \\
3 & 3 & 4 & 7.89 \\
4 & 3 & 7 & 5.59 \\
5 & 3 & 7 & 6.19 \\
6 & 3 & 7 & 5.71 \\
7 & 3 & 11 & 7.10 \\
8 & 3 & 11 & 6.65 \\
9 & 3 & 11 & 8.20 \\
10 & 5 & 4 & 4.93 \\
11 & 5 & 4 & 3.45 \\
12 & 5 & 4 & 2.88 \\
13 & 5 & 7 & 3.88 \\
14 & 5 & 7 & 5.71 \\
15 & 5 & 7 & 6.19 \\
16 & 5 & 11 & 9.44 \\
17 & 5 & 11 & 7.14 \\
18 & 5 & 11 & 7.67 \\
\hline
\end{tabular}

Drying temperatures at 100,110 and $120^{\circ} \mathrm{C}$, determined by the steam pressure inlet and the drying times, were set by the drums' rotation speed. After processing, the dehydrated product was separated by the blades of each drum, which was then collected and placed in polyethylene bags. The results showed that drum drying is a very fast process. The required drying time to eliminate $92.5 \%, 97.6 \%$ and $96.1 \%$ of the pomegranate peel water was 7.0,6.7 and $4.3 \mathrm{~min}$ at 100,110 and $120^{\circ} \mathrm{C}$, respectively. The drying time was considerably lower in comparison with the traditional hot air drying process. Initial moisture in the fresh pomegranate peel was $66.8 \pm 1.9 \mathrm{~g}$ water $/ 100 \mathrm{~g}$ of shell $(2.01 \pm 0.17 \mathrm{~g}$ water $/ \mathrm{g}$ DM), obtaining a final average moisture content of $5.0 \%, 1.6 \%, 2.6 \%$ at the above mentioned temperatures. As can be observed, the drum speed and steam pressure/heating temperature, are process variables to control the moisture content of the product. This criterion was considered for the design of the present research.

\section{Artificial neural networks}

In the search for an appropriate architecture, the number of neurons in the intermediate layer were varied to 75 neurons, and with 10 neurons in a hidden layer, 0.744 as the lower mean square error (MSE) (Figure 2) was obtained. A combination of the hidden layer transfer and the neuron output functions (Figure 3 ) was also done in order to analyze the MSE variation, choosing the hyperbolic tangent sigmoid transfer function with linear output (tansigpurelin).

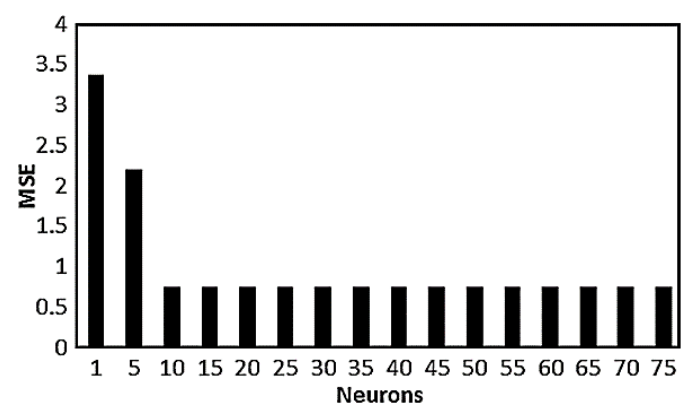

Figure 2. MSE variation based on the number of neurons in the hidden layer.

According to these findings, an architecture with entries (independent variables) was obtained: $p=3,3,3,3,3,5,5,5,5,5,5,5$ and $4,7,7,11,11,4,4,4,7,7,11,11$; with output (response variable) $t=7.89 ; 5.59 ; 6.19 ; 6.65$; $8.2 ; 4.93 ; 3.45 ; 2.88 ; 3.88 ; 6.19 ; 9.44 ; 7.14$, as well as a 0.001 learning rate, 0.1 moment coefficient, six (6) training stages and 10${ }^{1}$ goal error. The procedure was carried out according to the methodology reported by Rojas and Vásquez (2012) verifying the decreasing MSE (Figure 4). Observing that the error decreases without reaching the fixed target error at $10^{-1}$ and in the posttraining validation process with data: $p=[3$, 4]; $a=\operatorname{sim}(n e t, p) / p=[3,4] ; a=\operatorname{sim}($ net, $p) /$ $p=[3,7] ; a=\operatorname{sim}($ net, $p) / p=[3,11] ; a=\operatorname{sim}($ net, p) $/ p=[5,7] ; a=\operatorname{sim}($ net, p) $/ p=[5,11]$; $a=\operatorname{sim}($ net, $p)$; $a$ high value of mean absolute error between experimental values and the estimated values of $6.42 \pm 3.83 \%$ was obtained (Table 2), as well as a correlation coefficient (R) of 0.89 indicating a high dispersion (Figure 5), because there were insufficient data for an adequate training (12 treatments).

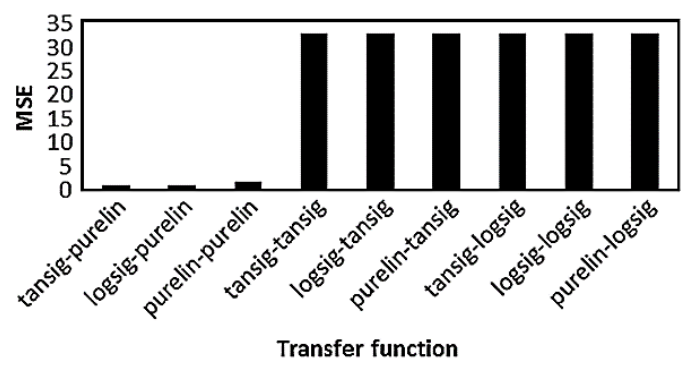

Figure 3. MSE variation based on the combinatorial of hidden layer transfer and output functions. 


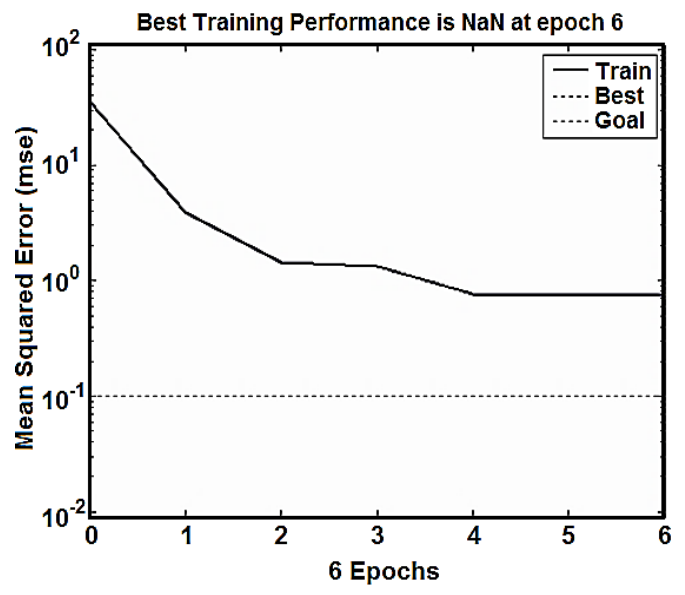

Figure 4. Error decreasing during ANN training.

Maran et al. (2013) carried out a comparative study of the predictive ability of mass transfer parameters of Carica papaya osmotic dehydration, using 17 treatments with ANN-Backpropagation and RSM-BoxBehnken design. The process independent variables were, temperature, osmotic solution concentration and agitation speed. They assessed percentage of water loss, weight reduction and solids gain. The same design was used to train the RNABackpropagacion. The results showed that RNA had a better predictive capacity than the MSR model with R-value of 0.996, 0.999, 0.998 and a mean absolute error of $0.377 \%$, $0.155 \%, 0.054 \%$, for water loss, weight reduction and solids gain, respectively. Benković et al. (2015) reported the modeling by ANN, of the changes in the physical and chemical properties of mixtures of cocoa powder, during fluidized bed agglomeration and drying by atomization. With a 59 data validation, ANN model (multilayer neural network Perceptron), predicted accurately the input parameters effect, simultaneously with output parameters (training: $R^{2}=0.969$, test: $R^{2}=0.945$; validation $R^{2}=0.934$ ). This demonstrates that an increase of the experimental data for one training, improves the ANN prediction.

Table 2

Data for ANN validation

\begin{tabular}{ccccc}
\hline $\begin{array}{c}\text { Pressure } \\
(\mathrm{atm})\end{array}$ & $\begin{array}{c}\text { Speed } \\
(\mathrm{rpm})\end{array}$ & $\begin{array}{c}\text { Moisture } \\
\text { experimental } \\
(\%)\end{array}$ & $\begin{array}{c}\text { Moisture } \\
\text { estimate } \\
(\%)\end{array}$ & $\begin{array}{c}\text { Absolute } \\
\text { error } \\
(\%)\end{array}$ \\
\hline 3 & 4 & 7.17 & 7.89 & 10.04 \\
3 & 4 & 7.97 & 7.89 & 1.00 \\
3 & 7 & 5.71 & 5.89 & 3.15 \\
3 & 11 & 7.10 & 7.42 & 4.51 \\
5 & 7 & 5.71 & 5.04 & 11.73 \\
5 & 11 & 7.67 & 8.29 & 8.08 \\
\hline & & & Average: & $6.42 \pm 3.83$ \\
\hline
\end{tabular}

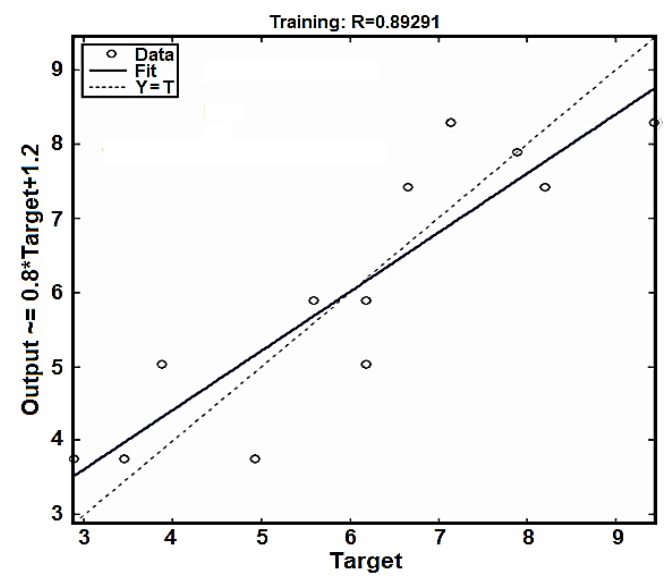

Figure 5. Correlation of the flakes moisture values obtained experimentally and estimated with ANN.

\section{Fuzzy Logic}

The first diffuse set input (independent variable) "speed" was performed with a universe of discourse of 4-11 rpm and three Gaussians membership relations (gaussmf): low [0.988 4], average [1.05 7.07] and high [1.22 11]. The second set "pressure" with the discourse universe of 3-5 atm with two gaussmf membership relations: low [0.481 $3]$ and high [0.456 5]. The output diffuse set "final moisture" (response variable) with the universe of discourse of 2.88-9.44\% with six gaussmf relations of membership: very low [0.26 3.75], low [0.363 5.26], average [0.372 5.83], high [0.413 7.31], very high [0.3754 7.68] and superhigh [0.247 8.08]. Finally, fuzzy associative memory (FAM) was built (Zhong et al., 2016), to represent the result of flakes moisture in each rule by the RDD pressure and speed combination (Table 3 ).

\section{Table 3}

FAM of the experimental variables of RDD and flakes moisture

\begin{tabular}{|c|c|c|}
\hline Speed (rpm) & Low & high \\
\hline $\begin{array}{c}\text { Low } \\
\text { Average } \\
\text { High }\end{array}$ & $\begin{array}{l}\text { Veryhigh } \\
\text { Average } \\
\text { High }\end{array}$ & $\begin{array}{c}\text { Very low } \\
\text { Low } \\
\text { Superhigh }\end{array}$ \\
\hline
\end{tabular}

Six (6) rules with the connection "and" were established, according to:

1. If the speed is low and the pressure is low then the final moisture is very high.

2. If the speed is medium, and the pressure is low then the final moisture is average.

3. If the speed is high and the pressure is low then the final moisture is high.

4. If the speed is low and the pressure is high then the final moisture is very low.

5. If the speed is medium and pressure is high then the final moisture is low.

6. If the speed is high and the pressure is high then the final moisture is super high. 


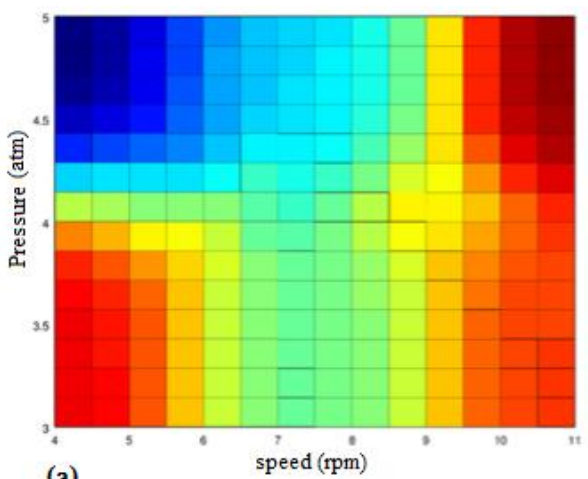

(a)

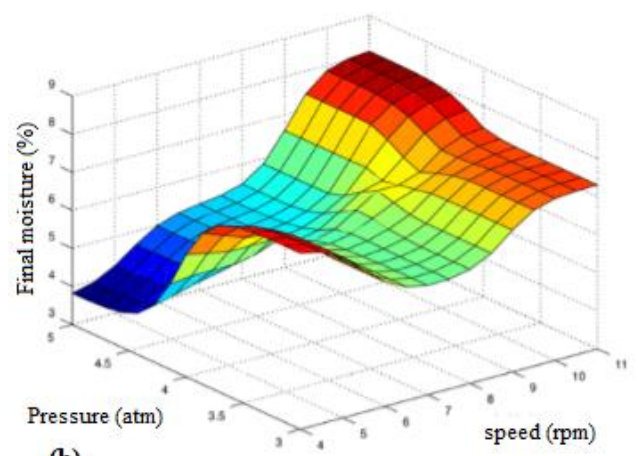

(b)

Figure 6. (a) Contour surface, and (b) three-dimensional surface of the flakes moisture as a function of the RDD speed and pressure.

In the present case, a multiple input single output system was used with the connection and (intersection). Inlets fuzzification occurs in the connection of the fuzzy inference; such operation determines the membership level between 0 and 1 ( 0 to 100 $\%$ ) of the fuzzy sets (Ramírez, 2014). When entering speed and pressure values, defuzzication outputs were obtained, with an exact moisture value. The results obtained are shown in Table 4, which denotes a low value of mean absolute error at $0.6 \pm 0.66 \%$. A correlation between the experimental values obtained from the average final flakes moisture in RDD and those estimated by the FL model, showed a determination coefficient of $R^{2}=0.99$, which established the consistency of the model.

Table 4

Flakes moisture values obtained experimentally and data estimated by FL

\begin{tabular}{ccccc}
\hline $\begin{array}{l}\text { Pressure } \\
(\mathrm{atm})\end{array}$ & $\begin{array}{c}\text { Speed } \\
(\mathrm{rpm})\end{array}$ & $\begin{array}{c}\text { Experimental } \\
\text { average } \\
\text { moisture } \\
(\%)\end{array}$ & $\begin{array}{c}\text { Estimated } \\
\text { moisture } \\
\text { Fuzzy logic } \\
(\%)\end{array}$ & $\begin{array}{c}\text { Absolut } \\
\text { error } \\
(\%)\end{array}$ \\
\hline 3 & 4 & 7.68 & 7.62 & 0.8 \\
3 & 7 & 5.83 & 5.87 & 0.7 \\
3 & 11 & 7.32 & 7.31 & 0.1 \\
5 & 4 & 3.75 & 3.82 & 1.9 \\
5 & 7 & 5.26 & 5.26 & 0.0 \\
5 & 11 & 8.08 & 8.07 & 0.1 \\
\hline & & & Average: & $0.6 \pm$ \\
& & & & 0.66 \\
\hline
\end{tabular}

In Figure 6 the contours and threedimensional surface of the flakes moisture dehydrated in the RDD is observed, where the lowest moisture is denoted by the blue color and the highest by the red. In Figure 7, $4.98 \%$ adequate moisture was obtained with an inlet of $6 \mathrm{rpm}$ speed and $5 \mathrm{~atm}$ pressure.

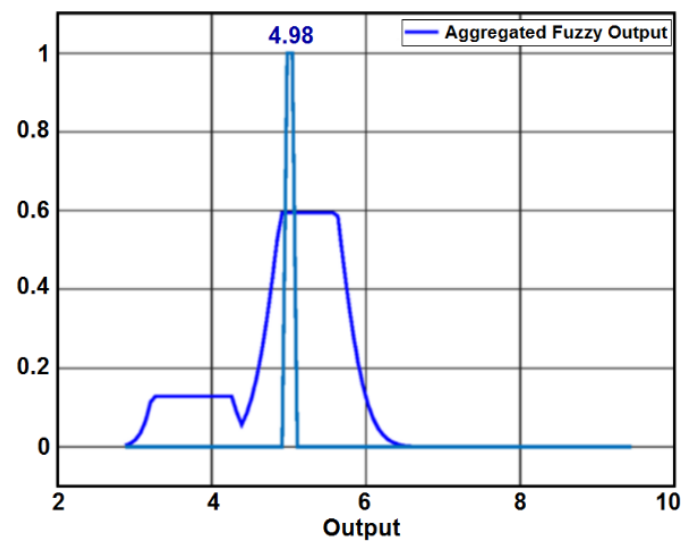

Figure 7. Defuzzified moisture output (4.98\%) with 6 rpm speed and $5 \mathrm{~atm}$ steam pressure in the RDD.

Tavakolipour et al. (2014) used FL and ANN to predict the moisture content of Zucchini slices (Cucurbita pepo) during the dehydration process in a tray dryer. As input variables, they used drying time, temperature and product thickness and as output variable, moisture proportion. 81 rules were used with the "and" operator and obtained an $R^{2}=0.919$. They found that the ANN with topology 3-20-20-1 had a better performance with $R^{2}=0.998$. Jafari et al. (2015) studied the temperature influence and the air speed of a fluidized bed dryer in onion dehydration. They compared non-linear regression techniques, $F L$ and ANN in estimating the drying dynamic behavior. They were among nine mathematical models with high performance prediction of drying kinetics $\left(R^{2}=0.999\right)$. Using $F L$ with traingular membership functions and Mamdani defuzzication method, they also obtained a high level of prediction accuracy $\left(\mathbf{R}^{2}=\right.$ 0.9971 to 0.9799 ) and with the use of ANNBackpropagation, with Levenberg-Marquardt training algorithm, transfer function hyperbolic sigmoidal tangent, 1000 training steps and topology $2-5-1$, they determined the best neural model in terms of statistical indices, with a $R^{2}=0.99956$. As can be seen, in the above cases the ANN had a better performance with a minimal difference to FL.

\section{Response Surface Methodology}

The quadratic function from 18 treatments was obtained (Equation 1) with a $\mathrm{R}^{2}: 0.77$ between experimental and estimated values 
with a high value of mean absolute error of $12.9 \pm 9.1 \%$. This can be explained by the use of an experimental bi-factorial design. A central composite rotational design (CCRD) with two factors (pressure and speed) and three replicates minimum at the central point is suitable and recommended (Montgomery and Runger, 2012).

Moisture $(\%)=20.36820-3.01122 * P-2.29602 *$

$S+0.08506 * S^{2}+0.32592 * P * S \quad$ (Eq. 1)

Where: P: pressure (atm), S: speed (rpm).

From the location of a region in the contour area (Figure 8) that allowed us to obtain a 5 $\%$ flakes moisture and using Equation 1 to specify values, flakes moisture value of 4.99 $\%$ to $5 \%$ was obtained, when pressure was 4.42 to $4.35 \mathrm{~atm}$ and the speed of 4-5 rpm respectively. By applying RSM with 13 experimental treatments with 5 repetitions at the central point, Thanh (2015) optimized pumpkin dehydration using RDD. The independent variables were the steam pressure between 300 to $400 \mathrm{kPa}$ and rotation speed between 0.5 and $1.5 \mathrm{rpm}$. With a steam pressure of $313.54 \mathrm{kPa}$ and speed of $1.27 \mathrm{rpm}$, he obtained pumpkin powder with low humidity, small color differences, high value of fibre and $\beta$ carotene, good sensory score, as well as polynomial equations of second order with a high value of $R^{2}(0.9504-0.9999)$. Thus, confirming the importance of the central points.

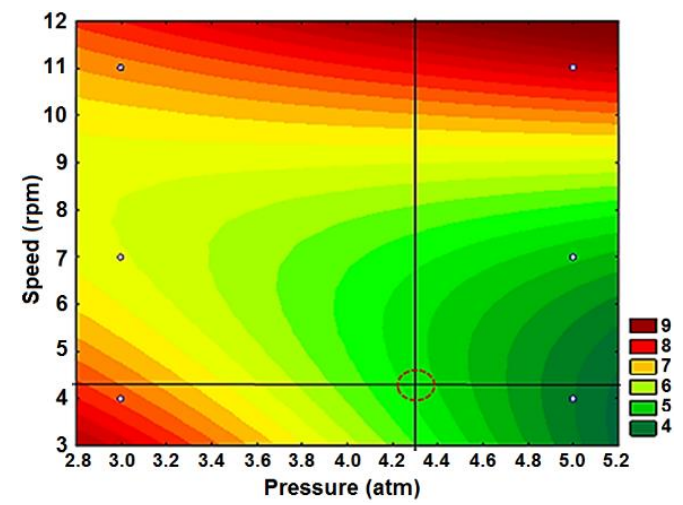

Figure 8. Contour surface of the operating pressure and the RDD rotational speed effect on the flakes moisture values.

\section{Genetic Algorithms}

Random populations were generated from a software data set, making up the chromosomes. These generated new offspring iteratively and using by default the genetic operators of selection, crossover and mutation until fully optimized. The generational iterations for the flakes moisture minimum optimization in the objective function (fitness) (Equation 1) (considered 5 $\%$ ) are denoted in Figure 9. A $5.06 \%$ value from generation 16 is observed. Table 5 shows the ranges of variables delimitations, where the fitness values are the flakes moisture values; $x(1)$ and $x(2)$ are the values of pressure and speed variables obtained with GA respectively. Using the mathematical function with $x(1)$ and $x(2)$ values (Equation 1), the values recorded in RSM column were obtained. A high estimation precision values of fitness obtained with $G A$ and RSM was observed.

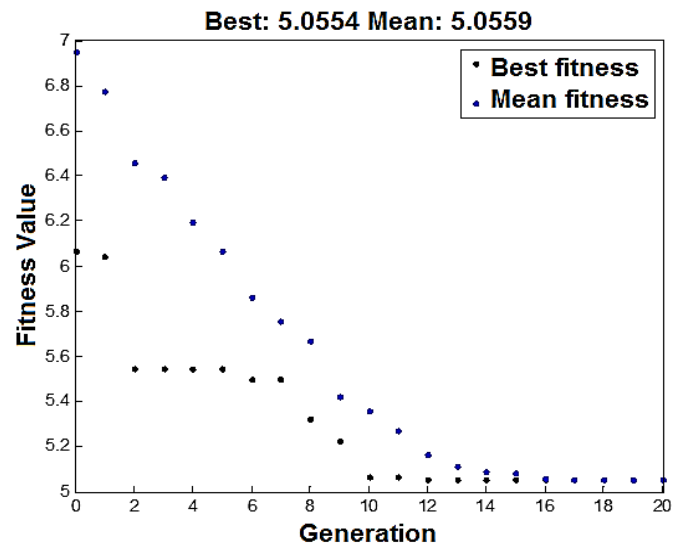

Figure 9. Generational iterations for the optimization of minimum flakes moisture value in the objective function.

Shahraki et al. (2014) studied the optimization of microwave pretreatment and frying of french style potato fries regarding quality attributes (moisture and oil content, as well as parameters of texture and color). They investigated the efficiency of the GA to improve the response of the models obtainned by RSM technique. GA-optimized models had a better response with the experimental results, than with those obtained by RSM models. Using GA. Rhaman et al. (2015), simulated and optimized the kinetics and the process of rice drying, which were carried out on a solar dryer with air supply at different temperatures. They applied the empirical Page's model equation as objective function; optimization was obtained with a population of 600 individuals, 50 generations, $1 \%$ mutation probability. In a similar way as in the present investigation of SPQK-based flakes, an equation was used as objective function to find the optimal process conditions.

Table 5

Fixed constraints ranges (Lower; Upper) to obtain the desired flakes moisture value according to objective function (fitness)

\begin{tabular}{cccccc}
\hline Lower & Upper $\begin{array}{c}\text { Foitness } \\
(\%)\end{array}$ & $\begin{array}{c}\text { Pressure } \\
(\mathrm{atm}) \\
\times(1)\end{array}$ & $\begin{array}{c}\text { Speed } \\
(\mathrm{rpm}) \\
\times(2)\end{array}$ & $\begin{array}{c}\text { RSM } \\
\text { Moisture } \\
(\%)\end{array}$ \\
\hline 4.3 & 4.30 & 5.068 & 4.30 & 5.218 & 5.068 \\
4.3 & 4.31 & 5.055 & 4.31 & 5.209 & 5.055 \\
4.3 & 4.40 & 5.263 & 4.395 & 3.136 & 5.262 \\
4.3 & 4.50 & 4.806 & 4.493 & 4.906 & 4.806 \\
\hline
\end{tabular}




\section{Conclusions}

Bi-factorial experimental design for the SPQK-based flakes moisture evaluation is limiting for modeling because of the effect of the variation of the steam pressure and RDD rotational speed. IA techniques (ANN, FL and GA) were applied to the experimental data obtained in order to assess its usefulness in these cases and their prediction capacity. The use of ANN did not allow a correct prediction of the experimental values due to the limitation of data for an adequate training. RSM was used in order to obtain the relationship equation between the experimental variables, which was used as the objective function with the GAs, allowing for moisture optimization. Therefore, it is recommended to integrate RSM with GA into studies of optimization. In the present research the use of FL among the variables, enabled the researchers to obtain the best fit prediction of experimental values. However, it does not necessarily constitute an exclusive technique, since the other Al techniques, depending on their experimental complexity, can possess advantages and limitations that should be evaluated before to their selection.

\section{References}

Amelia, L. 2012. Modelling of palm oil production using fuzzy expert system. Universitas Esa Unggul. Pp. 4. Available

http://www.esaunggul.ac.id/article/modelling-ofpalm-oil-production-using-fuzzy-expert-system/

Azadbakht, M.; Aghili, H.; Ziaratban, A.; Torshizi, M. 2017. Application of artificial neural network method to exergy and energy analyses of fluidized bed dryer for potato cubes. Energy 120: 947-958.

Benković, M.; Jurinjak, A.; Belščak-Cvitanović, A.; Lenart, A.; Domian, E.; Komes, D.; Bauman, I. 2015. Artificial neural network modelling of changes in physical and chemical properties of cocoa powder mixtures during agglomeration. LWT - Food Science and Technology 64(1): 140-148.

Carvalho, A.; Mattietto, R.; Bassinello, P.; Koakuzu, S.; Rios, A.; Maciel, R.; Carvalho, R. 2012. Processing and characterization of extruded breakfast meal formulated with broken rice and bean flour. Ciênc. Tecnol. Aliment., Campinas 32(3): 515-524.

Cheng, J.; Wang, X.; Si, T.; Zhou, F.; Zhou, J.; Cen, K. 2016. Ignition temperature and activation energy of power coal blends predicted with back-propagation neural network models. Fuel 173: 230-238.

Dao, S.; Abhary, K.; Marian, R. 2017. An innovative framework for designing genetic algorithm structures. Expert Systems with Applications 90: 196-208.

Devi, A.; Eyles, H.; Rayner, M.; Mhurchu, C.; Swinburn, B.; Lonsdale-Cooper, E.; Vandevijvere, S. 2014. Nutritional quality, labelling and promotion of breakfast cereals on the New Zealand market. Appetite 81:253-260.

Díaz-Cortés, M.; Cuevas, E.; Gálvez, J.; Camarena, O. 2017. A new metaheuristic optimization methodology based on fuzzy logic. Applied Soft Computing 61: 549-569.

Galaz, P.; Valdenegro, M.; Ramírez, C.; Nuñez, H.; Almonacid, C.; Simpson, R. 2017. Effect of drum drying temperature on drying kinetic and polyphenol contents in pomegranate peel. Journal of Food Engineering 208: 19-27.

Guiné, R.; Barroca, M.; Gonçalves, F.; Alves, M.; Oliveira, S.; Mendes, M. 2015. Artificial neural network modelling of the antioxidant activity and phenolic compounds of bananas submitted to different drying treatments. Food Chemistry 168: 454-459.

Jafari, S.; Ganje, M.; Dehnad, D.; Ghanbari, V. 2015. Mathematical, fuzzy logic and artificial neural network modeling techniques to predict drying kinetics of onion. Journal of Food Processing and Preservation, 1-11.

Kant, G.; Singh, K. 2015. Predictive Modelling and Optimization of Machining Parameters to Minimize Surface Roughness using Artificial Neural Network Coupled with Genetic Algorithm. Procedia CIRP 31: 453-458.

Maran, J.; Sivakumar, V.; Thirugnanasambandham, K.; Sridhar, R. 2013. Artificial neural network and response surface methodology modeling in mass transfer parameters predictions during osmotic dehydration of Carica papaya L. Alexandria Engineering Journal 52: 507-516.

Martinez-Conesa, E.; Egea, J.; Valentin, M.; Toledo, C.; Meseguer-Valdenebro, J. 2017. Optimization of geometric parameters in a welded joint through response surface methodology. Construction and Building Materials 154: 105-114.

Milczarek, R.; Ferry, J.; Alleyne, F.; Olsen, C.; Olson, D.; Winston, R. 2017. Solar thermal drum drying performance of prune and tomato pomaces. Food and Bioproducts Processing 106: 53-64.

Montgomery, D.; Runger, G. 2012. Probabilidad y estadística aplicadas a la ingeniería. 2da Edición Edit. Limusa S.A. México. D.F., 817 pp.

Muddle, J.; Kirton, S.; Parisini, I.; Muddle, A.; Murnane, D.; Ali, J.; Brown, M.; Page, C.; Forbes, B.; 2017. Predicting the Fine Particle Fraction of Dry Powder Inhalers Using Artificial Neural Networks. Journal of Pharmaceutical Sciences 106(1): 313-321.

Nadian, M.; Rafiee, F.; Aghbashlo, M.; Hosseinpour, S.; Mohtasebi, S. 2015. Continuous real-time monitoring and neural network modeling of apple slices color changes during hot air drying. Food and Bioproducts Processing 94: 263-274.

Navruz-Varli, S; Sanlier, N. 2016. Nutritional and health benefits of quinoa (Chenopodium quinoa Willd.). Journal of Cereal Science 69: 371-376.

Nasiri, S.; Khosravani, M.; Weinberg, K. 2017. Fracture mechanics and mechanical fault detection by artificial intelligence methods: A review. Engineering Failure Analysis 81: 270-293.

Nawi, N.; Khan, A.; Rehman, M. 2013. A New Levenberg Marquardt Based Back Propagation Algorithm Trained with Cuckoo Search. Procedia Technology 11: 18-23.

Rhaman, M.; Mustayen, A.; Mekhilef, S.; Saidur, R. 2015. The Optimization of Solar Drying of Grain by Using a Genetic Algorithm. International Journal of Green Energy 12(12): 1222-1231.

Paucar-Menacho, L.; Peñas, E.; Dueñas, M.; Frias, J.; Martínez-Villaluenga, C. 2017. Optimizing germination conditions to enhance the accumulation of bioactive compounds and the antioxidant activity of kiwicha (Amaranthus caudatus) using response surface methodology. LWT-Food Science and Technology 76B: 245-242.

Ramírez, M. 2014. Modelo de reglas difuso para el análisis y evaluación de MOOCs con la norma UNE 66181 de calidad de la formación virtual. Tesis de Doctorado, Universidad Pablo de Olavide, Sevilla. España. 283 pp.

Ramos, J.; Kirjoranta, S.; Tenitz, S.; Penttilä, P.; Serimaa, R.; Lampi A.; Jouppila, K. 2013. Use of amaranth, quinoa and kañiwa in extruded corn-based snacks. Journal of Cereal Science 58: 59-67.

Rojas, J.; Vasquez, V. 2012. Prediction by Artificial Neural Networks (ANN) of the diffusivity, mass, moisture, volume and solids on osmotically 
dehydrated yacon (Smallantus sonchifolius). Scientia Agropecuaria 3: 201-214.

Shahraki, H.; Ziaiifar, A.; Kashaninejad, S.; Ghorbani, M. 2014. Optimization of pre-fry microwave drying of French fries using response surface methodology and genetic algorithms. Journal of Food Processing and Preservation 38(1): 535-550.

Sjafrina, N.; Aminah, S. 2014. Consumers Preferences to Sweet Potato Flakes (Spf) from Sweet Potato Pasta as A Raw Material, with Enrichment Mung Bean Flour as Source Protein. International Journal on Advanced Science Engineering 4(3): 67-60.

Thanh, D. 2015. Optimization of drum drying process parameters for pumpkin powder production and its substitution in rice noodles. Journal of Science C:
Agricultural Sciences, Fisheries and Biotechnology 3(3): 149-160.

Tavakolipour, H.; Mokhtarian, M.; Kalbasi-Ashtari, A. 2014. Intelligent Monitoring of Zucchini Drying Process Based on Fuzzy Expert Engine and ANN. Journal of Food Process Engineering 37(5): 474-481.

Wang, S.; Nie, S.; Zhu, F. 2016. Chemical constituents and health effects of sweet potato. Food Research International 89(1): 90-116.

Woolfe, J. 1992. Sweet potato: an untapped food source. Cambridge University Press. Cambridge, UK. 643 pp.

Zhong, Ch.; Pedrycz, W.; Li, Z.; Wang, D.; Li, L. 2016. Fuzzy associative memories: A design through fuzzy clustering. Neurocomputing 173(3): 1154-1162. 